\title{
The Acquisition of Preposition + Article Contractions in L3 Portuguese among Different L1-Speaking Learners: A Variationist Approach
}

\author{
Adriana Picoral ${ }^{1, *}$ and Ana Maria Carvalho ${ }^{2, *}$ \\ 1 School of Information, University of Arizona, Tucson, AZ 85721, USA \\ 2 Department of Spanish and Portuguese, University of Arizona, Tucson, AZ 85721, USA \\ * Correspondence: adrianaps@arizona.edu (A.P.); anac@arizona.edu (A.M.C.)
}

Received: 1 September 2020; Accepted: 21 October 2020; Published: 27 October 2020

check for updates

\begin{abstract}
This paper sheds light on the paths of third language (L3) acquisition of Portuguese by Spanish-English speakers whose first language is Spanish (L1 Spanish), English (L1 English), or both in the case of heritage speakers of Spanish (HL). Specifically, it looks at the gradual acquisition of a categorical rule in Portuguese, where some prepositions are invariably contracted with the determiner that follows them. Based on a corpus of 1910 written assignments by Portuguese L3 learners, we extracted 21,879 tokens in obligatory contraction contexts and submitted them to a multivariate analysis. This analysis allowed for the investigation of the impact of linguistic (type of preposition and definite article number and gender) and extra-linguistic factors (course level and learner's language background), with logistic regression modeling with sum contrasts and individual as a random effect. While results point to some clear similarities across the three language groups-all learners acquired the contractions in a u-shaped progression and used more contractions with the $a$ preposition and fewer with the por preposition-participants acquire contractions at a higher rate when the article is singular than when it is plural, and in the case of HL speakers, more so when the article is masculine than when it is feminine. These results confirm the facilitatory role of a previously acquired language (i.e., Spanish) that is typologically similar to the target language (i.e., Portuguese) in transfer patterns during L3 acquisition.
\end{abstract}

Keywords: usage-based approach; third language acquisition; morphology

\section{Introduction}

Since Dickerson's (1975) seminal work that applied the variable rule analysis to study the gradual acquisition of L2 English sounds by Japanese speakers, important work has shown that the methodological and conceptual tools offered by studies of language variation and change, or variationist sociolinguistics, are ideal to capture the gradual nature of the implementation and spread of target-like linguistic forms in a foreign language system (summarized in Preston 1996; Tarone 2007; Geeslin and Long 2014). This paper expands this line of research by including the variable rule analysis in the investigation of third language (L3) acquisition of Portuguese by Spanish-English speakers whose first language is Spanish (L1 Spanish), English (L1 English), or both in the case of heritage speakers of Spanish (HL). Our goal is to shed light on differential paths of acquisition and different transfer patterns that are revealed by linguistic variation in L3 use among these groups of learners.

\subsection{Usage-Based Approaches to Additional Language Acquisition}

There are a number of usage-based approaches to second language acquisition that argue that language learning is usage-driven (Eskildsen and Cadierno 2015; Geeslin and Long 2014; Wulff and 
Ellis 2018), but to our knowledge, such an approach has not been applied to studies of L3 acquisition. In a usage-based approach to second language acquisition, it is believed that learning takes place in a bottom-up fashion, with repeated experiences with language being the basis for linguistic structure in the mind (Bybee 2008; Eskildsen and Cadierno 2015; Geeslin and Long 2014). This usage-based perspective to language learning assumes that the language input that learners are exposed to, combined with general cognitive processes, is the main source for their language acquisition (Tomasello 2009; Wulff and Ellis 2018), as opposed to internally driven language-specific mechanisms of language acquisition. Language constructions are seen as "neuromotor routines with movable parts" that are built naturally, dynamically, and unconsciously, based on practice (Bybee 2008).

Language constructions refer to conventionalized form-function mappings of different levels of complexity and abstraction that carry certain semantic and discourse functions in a speech community and occur at all levels of grammatical analysis (morphological, syntactic, and pragmatic) (Ellis 2015; Goldberg 2006). Since construction learning is dependent on specific characteristics of the linguistic input that learners receive, such as saliency of the language construction, learners do not acquire all constructions at the same rate (Wulff and Ellis 2018). A memory representation is first built with a first encounter with a language construction, then each new exemplar is compared to the existing representation of that construction, with gradual accumulative adaptations with each encounter (Geeslin and Long 2014). As a result, frequency of constructions affects both language development and entrenchment (Ellis 2015; Wulff and Ellis 2018). From this perspective, language development is slow and gradual, starting with more concrete (e.g., single content words) and moving to more abstract constructions, such as transitives and locatives (Ellis 2015).

Regarding the acquisition of morphology, it has been documented that "grammatical morphemes and closed-class constructions are more difficult to learn than open-class constructions" (Wulff and Ellis 2018, p. 43), which might be explained by the lack of phonetic substance and stress (i.e., salience) placed on closed-class constructions. Scholars agree that, despite the difficulties that are involved in second language acquisition, which stem from filtering the target input through a previously acquired language and the fact that most L2 learners are adults with complex identity and socialization issues, any morphosyntactic pattern in the target language can be acquired (Bybee 2008).

Although L1 is considered a factor that affects additional language acquisition (viewed both as a help and a hindrance), usage-based research has rarely addressed language learners who already speak multiple languages. In fact, research in L3 acquisition has been fruitful in the last two decades, with a number of cognitive models of L3 acquisition proposed (De Angelis 2007; Rothman 2010a). In the next section, we discuss previous findings for L3 Portuguese acquisition by Spanish-English speakers and how it relates to a usage-based approach to second language acquisition.

\subsection{L3 Portuguese Acquisition by Spanish-English Speakers}

A few L3 acquisition models have been proposed in the last decade (De Angelis 2007; Forsyth 2014), with a number of studies on L3 Portuguese by Spanish-English speakers offering support to the Typological Primacy Model (Rothman 2010a). This L3 acquisition model argues that the language (i.e., either a first or an additional language) that shares more typological similarities is the only source of cross-linguistic influence on the L3 (Alonso and Rothman 2016; Amaro 2017; Amaro et al. 2015). For the case of L3 Portuguese by Spanish-English speakers, the most typologically similar language to Portuguese is Spanish (compared to English) (Amaro et al. 2015; Giancaspro et al. 2015). Based on this assumption, we would expect a facilitatory role of Spanish contractions ( $a l$ and $\mathrm{del}$ ) in the realization of contractions in Portuguese, regardless of the learners' linguistic background (L1 English, L1 Spanish, and Spanish Heritage speakers).

L3 acquisition of Portuguese is a fruitful platform to investigate Rothman's formal model of L3 acquisition, due to the presence of Spanish-speaking immigrants (i.e., L1 Spanish L2 English speakers), heritage speakers of Spanish (i.e., L1 English L1 Spanish), and English-speaking learners of Spanish (i.e., L1 English L2 Spanish) in the Portuguese classrooms. This is especially relevant to the study of the 
acquisition of morphological rules, since, until recently, many scholars were skeptical that morphology and syntax could be transferred from a non-native language to another (De Angelis 2007; Forsyth 2014). More recently, L3 Portuguese acquisition studies contradict this no-transfer assumption by showing syntactic/morphosyntactic transfer of Differential Object Marking (DOM) (Giancaspro et al. 2015), object clitic pronouns (Montrul et al. 2010), and subjunctive mood (Carvalho and Bacelar Da Silva 2006; Child 2014).

In Giancaspro et al.'s (2015) investigation of the infelicitous transfer of Spanish DOM to Portuguese based on grammaticality judgments, they found that Spanish influences the Portuguese case marking regardless of the context where Spanish was acquired (L1, L2, or LH). Montrul et al. (2010) looked at object clitic pronoun placement in L3 Portuguese among similar groups, and found, based on elicited oral production tasks, that L1 Spanish performed slighted better than the L1 English group, but transfer from Spanish was prevalent across all groups. In addition, Child (2014), based on sentence completion and grammaticality judgment tests, considered the acquisition of mood distinctions in L3 Portuguese, and again found that all three groups of Spanish-English speakers showed a tendency to transfer from Spanish into Portuguese. Finally, Rothman (2010b), in a series of experimental tests, investigated subject-verb order in interrogatives in L3 Portuguese and found cross-linguistic influence from Spanish for two types of Spanish-English speakers (i.e., L1 Spanish L2 English, and L1 English L2 Spanish).

All these experimental studies corroborated Rothman's Typological Primacy Model. The current study proposes to add to this investigation by testing this model against non-experimental data collected from a learner's corpus and submitted to variationist analysis. Following the usage-based theoretical framework, this analysis prioritizes language use instead of reflections about language use as data, given that it presupposes that a learner's linguistic system is grounded in "usage events," as claimed to be the case for L1 systems (Kemmer and Barlow 2000).

\section{The Current Study}

The current study aims at adding to the L3 acquisition research by taking a linguistic variation approach to obligatory preposition and article contractions in Portuguese produced by Spanish-English speakers. As such, this study's goal is to shed light on differential paths of acquisition and different transfer patterns that are revealed in L3 use among these groups of learners. Specifically, we look at the acquisition of a categorical rule in Portuguese, where some prepositions are invariably contracted with the determiner that follows them $(1 \mathrm{a}-\mathrm{b})$. In the systems of the previously acquired languages, prepositions and determiners are either never contracted (English, 2a-b), or contracted in some cases through similar processes, depending on the preposition and the determiner's gender and number (Spanish, 3a-b).

$\begin{array}{ll}\text { a. } & \text { Eu nadei no rio } \\ & \text { I swam in+the } \text { masc.sing. }_{\text {river }} \\ \text { a. I swam in the river } & \text { I swam in the river } \\ \text { a. Yo nade en el río } \\ \text { I swam in the river } \\ \text { 'I swam in the river' }\end{array}$
b. Eu vim do rio I came from the thasc.sing. river
b. I came from the river I came from the river
b. Yo vine del río

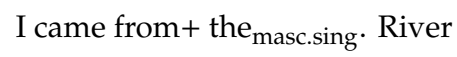 'I came from the river'

Table 1 presents the cases where contractions (i.e., a merger of a preposition and a definite article followed by loss of phonetic material) are obligatory in Portuguese, absent in English, and dependent on the preposition and the properties of the determiner in Spanish. Note that articles in Spanish and in Portuguese encode gender and number information. 
Table 1. Target preposition + definite article contractions that are obligatory in Portuguese, showing no contractions in English and two instances of contractions in Spanish (i.e., del and al).

\begin{tabular}{|c|c|c|c|}
\hline Preposition Type & Portuguese & Spanish & English \\
\hline a & $\begin{array}{c}a+a=a ̀ \\
a+o=a o \\
a+a s=a ̀ s \\
a+o s=a o s\end{array}$ & $\begin{array}{c}a+l a=a l a \\
a+e l=a l \\
a+\text { las }=a \text { las } \\
a+\text { los }=a \text { los }\end{array}$ & to + the $=$ to the \\
\hline de & $\begin{aligned} \mathrm{de}+\mathrm{a} & =\mathrm{da} \\
\mathrm{de}+\mathrm{o} & =\mathrm{do} \\
\mathrm{de}+\mathrm{as} & =\mathrm{das} \\
\mathrm{de}+\mathrm{os} & =\mathrm{dos}\end{aligned}$ & $\begin{array}{c}\text { de }+ \text { la }=\text { de la } \\
\text { de }+ \text { el }=\text { del } \\
\text { de }+ \text { las }=\text { de las } \\
\text { de }+ \text { los }=\text { de los }\end{array}$ & from + the $=$ from the \\
\hline em & $\begin{aligned} \mathrm{em}+\mathrm{a} & =\mathrm{na} \\
\mathrm{em}+\mathrm{as} & =\text { nas } \\
\mathrm{em}+\mathrm{o} & =\text { no } \\
\mathrm{em}+\mathrm{os} & =\text { nos }\end{aligned}$ & $\begin{array}{c}\text { en }+ \text { la }=\text { en las } \\
\text { en }+ \text { el }=\text { en el } \\
\text { en }+ \text { las }=\text { en las } \\
\text { em }+ \text { los }=\text { en los }\end{array}$ & in + the $=$ in the \\
\hline por & $\begin{array}{c}\text { por }+a=\text { pela } \\
\text { por }+o=\text { pelo } \\
\text { por }+a s=\text { pelas } \\
\text { por }+o s=\text { pelos }\end{array}$ & $\begin{aligned} \text { por }+\mathrm{la} & =\text { por la } \\
\text { por }+\mathrm{el} & =\text { por el } \\
\text { por }+ \text { las } & =\text { por las } \\
\text { por }+ \text { los } & =\text { por los }\end{aligned}$ & by + the $=$ by the \\
\hline
\end{tabular}

Contrastively, one observes that while these four prepositions in Portuguese categorically require contraction with all definite articles, Spanish does so only in two cases (prepositions $a$ and de followed by masculine singular definite article $e l$ ), and English does not contract at all. The phenomenon of contractions between a preposition that is lexically specified to trigger contractions with some determiners (Nunes and Ximenes 2008) is also found in Italian, French, and Galician. Adopting the theory of Distributed Morphology, Ximenes (2004) proposed that these contractions in Portuguese are the result of "two operations happening in the morphological component: merger followed by fusion" (p. 182). The author formalized this process as follows: first, two independent terminal nodes (a) fuse into one terminal node (b), and once the two nodes are adjacent, they merge (Figure 1).

a. Structure that enters morphology:

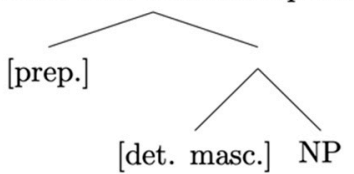

b. Application of merger: nodes become sisters

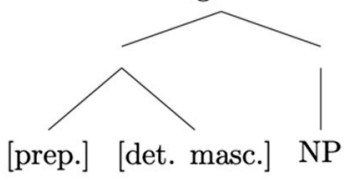

Figure 1. Two operations behind contractions in Portuguese (Ximenes 2004, p. 182).

This process is not necessarily understood and replicated by adults learning Portuguese as a second or third language. In fact, Amaral and Meurers (2009) showed that learners tend to interpret L2 Portuguese contractions as "a single, atomic entity," showing that they are not "fully aware of the compositional nature of contractions in Portuguese" (p. 585). Thus, it will be important to consider preposition type, and gender and number of the determiner in the analysis of acquisition of L3 Portuguese, since it is likely that learners may produce contractions variably before they learn how to generate the process that will produce them categorically. The idea is to see if the learners' initial use of the contraction system is more lexically-restricted than rule-induced, which is predicted by generative accounts. In addition, in revealing the linguistic contexts that lead to the gradual 
paths of the acquisition of the contraction rule, this paper considers the contexts where Spanish and Portuguese coincide (shown in Table 1) in order to investigate the role of linguistic congruency in third language acquisition.

Brito (2018) offered a study that, similar to the current one, looks at the acquisition of Portuguese contractions by L3 Portuguese learners whose previously acquired languages are Spanish and English. Based on nine participants engaged in oral interactions with L1 Portuguese speakers, the author analyzed only contractions with de prepositions (i.e., "from," "of") and included in the analysis the determiner's gender and number and the preceding word. Albeit the low number of tokens (a total of 104), Brito's (2018) study pinpoints the importance of gender marking of the determiner in the realization of contractions, since his results show that contractions that involve feminine articles favored non-target-like contractions, while masculine articles favored target-like contractions. The author explained that feminine gender assignment adds complexity to the task of making contractions, and pointed out the need to analyze mastering of the grammatical gender parallel to the application of the contraction rule.

The variable use of preposition-determiner contractions in L3 use is illustrated by a "super token" (Tagliamonte 2006, p. 96) in an example extracted from our learner's corpus (4), where the student fails to amalgamate the preposition em ("in") with the determiner $o$ ("the," MASC) in the first token but applies the contraction rule in the following context by contracting the same preposition with determiner $a$ ("the," FEM).

Os estados em o Nordeste de Brasil são Bahia, Alagoas, Pernambuco, Paraíba, Ceará,

The states in DET Northeast of Brazil are Bahia, Alagoas, Pernambuco, Paraíba, Ceará,

'The states in the Brazilian Northeast are Bahia, Alagoas, Pernambuco, Paraíba, Ceará,

Sergipe, Piauí e Maranhão. Incluído na região é a floresta amazónica.

Sergipe, Piauí and Maranhão. Included in + DET region is the forest Amazon.

Sergipe, Piauí and Maranhão. Included in the region is the Amazon forest.'

The variable use of contractions among L3 Portuguese learners, evidenced in example (4), leads us to ask the following:

1. Are obligatory contractions acquired at the same pace, regardless of L3 learner's L1?

2. Are obligatory contractions acquired at the same pace, regardless of linguistic contexts across different L1 groups, or are they acquired gradually according to the preposition type, and article gender and number?

3. Do quantitative results bring evidence to Rothman's Typological Primacy Model (Rothman 2010a), which predicts transfer from Spanish due to its similarity to Portuguese, which would be revealed by a preference for $d e+o=d o$ (Spanish $d e l$ ) and $a+o=a o$ (Spanish al) due to surface similarity between Portuguese and Spanish?

We hypothesize that if Spanish-English speakers transfer contraction knowledge from English to L3 Portuguese, there will be no difference of acquisition rate across different contraction constructions. If transferring from Spanish, contractions with the prepositions $d e$ and $a$ will be acquired before $\mathrm{em}$ and por, and article number might play a stronger role in acquisition than article gender.

Regarding contingency (i.e., form-function association), compared to English all obligatory contractions in Portuguese are all equally contingent. When compared to Spanish, however, singular masculine articles contracted with preceding $d e$ and $a$ prepositions (i.e., del and al) have a form-function mapping more similar to Portuguese. On the other hand, the contraction with por preposition in Portuguese (e.g., pelo) has the same form in Spanish with a completely different meaning (i.e., hair), which we predict will block (Ellis 2006) the correct form-function mapping in Portuguese. Here again we hypothesize that if Spanish-English speakers transfer contraction knowledge from English to L3 Portuguese, there will be no difference of acquisition rate across different contractions. If transferring 
from Spanish, contractions with the prepositions $d e$ and $a$ will be acquired before em and por, and por will be the last preposition contraction to be acquired due to blocking.

Finally, learned attention relates to the status of Spanish and English that our participants have experienced, namely, whether they have acquired either language before the other. If the Typological Primacy Model (Rothman 2010a) holds, all Spanish-English speakers acquiring Portuguese will filter the input they receive in Portuguese through Spanish.

\section{Materials and Methods}

\subsection{Participants and Corpus}

In order to answer these questions, we used an L3 Portuguese learner corpus comprising the written Portuguese production of 212 Spanish-English speakers divided into three groups: 72 L1 English L2 Spanish speakers (i.e., L1 English), 36 L1 Spanish L2 English speakers (i.e., L1 Spanish), and 104 L1 Spanish/English speakers (i.e., heritage speakers of Spanish or Spanish Heritage). Note that although our choice of written production is an unusual source for usage-based research, assessment tools in language classrooms are mostly based on written tasks. Our contribution to L3 acquisition is innovative in our choice of mode, as it reconciles research and classroom practices.

The participants' linguistic backgrounds were extracted from their own characterizations of their previous experience with language. Participants who chose the option "I was born in a Spanish-speaking country and lived there until at least 5 years old" were considered L1 Spanish speakers, the ones who chose "I was exposed to Spanish as a child in my household in the United States" were considered speakers of Spanish as a heritage language, and the ones who chose "I have learned Spanish in a classroom setting later in life" were considered L1 English speakers.

All participants were enrolled in a Portuguese language program at a large university in the Southwest of the United States, and all texts collected were submitted as course assignments for this program. As such, all participants came from the same learning context. A total of 1910 texts were used in this study, divided into three L3 Portuguese courses: 933 texts for L3 Portuguese Level 1, 519 texts for Level 2, and 458 texts for Level 3. Level 1 consisted of a first semester of Portuguese for Spanish speakers, Level 2 was the second semester, and Level 3 the third and final language course designed to teach Portuguese to Spanish speakers. Level of proficiency in this study was determined solely based on the course the student was enrolled in in the Portuguese language program. We acknowledge that course enrollment was a proxy for proficiency. However, a set of learning outcomes for each of the three courses was aligned with desirable proficiency levels, summarized in Table 2.

Table 2. Student learning outcomes and expected level of proficiency for each level.

\begin{tabular}{clcl}
\hline Level & Student Learning Outcomes & $\begin{array}{c}\text { Expected Level of Proficiency } \\
\text { (ACTFL Guidelines }{ }^{1} \text { ) }\end{array}$ & Description of Written Tasks \\
\hline 1 & $\begin{array}{l}\text { comprehend and communicate } \\
\text { main ideas and supporting } \\
\text { details on familiar topics using a } \\
\text { series of connected sentences in } \\
\text { both oral and written form }\end{array}$ & intermediate low & $\begin{array}{l}\text { biweekly written assignments, } \\
\text { topic-based (e.g., describe } \\
\text { your family) }\end{array}$ \\
\hline & $\begin{array}{l}\text { comprehend and communicate } \\
\text { main ideas and supporting } \\
\text { details and express own } \\
\text { thoughts on a variety of topics in } \\
\text { multiple time frames in both } \\
\text { written and oral form }\end{array}$ & intermediate mid & $\begin{array}{l}\text { weekly written assignments (e.g., } \\
\text { choose a work of art that you like, } \\
\text { describe it, and explain what you } \\
\text { like about it) }\end{array}$ \\
\hline & $\begin{array}{l}\text { comprehend and communicate } \\
\text { information and opinion in } \\
\text { discussions about familiar and } \\
\text { social topics and connect } \\
\text { academic experience to their } \\
\text { personal and professional lives }\end{array}$ & & intermediate high \\
& & & $\begin{array}{l}\text { genre-based written assignments } \\
\text { (e.g., gastronomic memory, trip } \\
\text { report, news article) }\end{array}$ \\
\hline
\end{tabular}


The type of written task assigned to each level varied according to level, as seen in Table 2, following the expected proficiency for that level. In Level 1, L3 Portuguese wrote mostly paragraphs (mean length of 137 words) related to the topic being studied (e.g., individual personality, family description, etc.). In Level 2, students were asked to express their own opinions and thoughts on topics such as art and current events in weekly written assignments (mean length of 276 words). In Level 3, students were required to make more connections between their personal and professional lives and their larger social contexts in genre-based written assignments (mean length of 449 words).

Table 3 shows the distribution of participants, text count, and word count extracted from the corpus across L1 background groups. Table 4 displays the same information, but across the L3 Portuguese course level. Note that total N (i.e., number of participants) differed across the two tables due to longitudinal data (i.e., 63 participants were repeated across at least two L3 Portuguese course levels in Table 4).

Table 3. Distribution of participants, texts, and total word count across the three L1 background groups.

\begin{tabular}{cccc}
\hline & Participants (N) & Text Count & Word Count \\
\hline L1 English & 72 & 676 & 162,782 \\
Spanish Heritage & 104 & 924 & 229,644 \\
L1 Spanish & 36 & 310 & 84,750 \\
TOTAL & $\mathbf{2 1 2}$ & $\mathbf{1 9 1 0}$ & $\mathbf{4 7 7 , 1 7 6}$ \\
\hline
\end{tabular}

Table 4. Distribution of participants, texts, total word count, and average text size across the Table 3 Portuguese courses. Note that the difference in total number of participants is due to 63 participants being in more than one level (longitudinal data).

\begin{tabular}{ccccc}
\hline & Participants (N) & Text Count & Total Word Count & Average Text Size \\
\hline Level 1 & 138 & 933 & 128,104 & 137 \\
Level 2 & 81 & 519 & 143,446 & 276 \\
Level 3 & 56 & 458 & 205,626 & 449 \\
TOTAL & $\mathbf{2 7 5 ^ { 2 }}$ & $\mathbf{1 9 1 0}$ & $\mathbf{4 7 7 , \mathbf { 1 7 6 }}$ & $\mathbf{2 5 0}$ \\
\hline
\end{tabular}

All subjects gave their informed consent for inclusion before they participated in the study. The study was conducted in accordance with the Declaration of Helsinki, and the protocol was approved by the Ethics Committee of the University of Arizona (Protocol Number: 1612053946).

\subsection{Analysis}

Tokens for prepositions and article combinations that constituted obligatory contractions in Portuguese were automatically extracted with a Python script written by the first author. These were then hand checked for accuracy, with a total of 21,879 tokens left. Table 5 shows the distribution of token frequency per L1 group, with mean token count per participant. Table 6 displays the same information, but across the L3 Portuguese course level.

1 The complete American Council on the Teaching of Foreign Languages (ACTFL) guidelines can be found at https: //www.actfl.org/.

2 The total $\mathrm{N}$ (i.e., number of participants) here differs from the $\mathrm{N}$ in Table 3 due to longitudinal data (i.e., 63 participants were repeated across at least two L3 Portuguese course levels). 
Table 5. Distribution of token counts per L1 group, and mean token count per participant.

\begin{tabular}{ccc}
\hline & Total Token Count & Mean Token Count Per Participant \\
\hline L1 English & 7665 & 106 \\
Spanish Heritage & 10,484 & 102 \\
L1 Spanish & 3730 & 104 \\
TOTAL & $\mathbf{2 1 , 8 7 9}$ & \\
\hline
\end{tabular}

Table 6. Distribution of token counts per L3 level, and mean token count per participant.

\begin{tabular}{ccc}
\hline & Total Token Count & Mean Token Count Per Participant \\
\hline Level 1 & 5817 & 43 \\
Level 2 & 6664 & 82 \\
Level 3 & 9398 & 168 \\
TOTAL & $\mathbf{2 1 , 8 7 9}$ & \\
\hline
\end{tabular}

Logistic regression with sum contrasts was run in R (R Core Team 2020) with the lme4 package (Bates et al. 2015). Sum contrasts regression modeling has been extensively used in variable rule analysis software (e.g., GoldVarb, Rbrul) (Johnson 2009). Finally, we added participant as a random effect to our logistic regression models, which has the effect of grouping the tokens from the same speaker, avoiding the problem of one speaker's behavior skewing the entire model (Tagliamonte 2012). This type of analysis outputs an overall mean (i.e., input or probability of the reference variant being realized) estimate in log odds, with each factor level estimate representing the deviation from the group mean. We converted the log odds to probabilities (i.e., factor weights or FWs). A probability weight that is higher than 0.5 means that when present, that factor will favor the contraction, while a probability weight that is lower than 0.5 means that when present, that factor will disfavor the contraction. The closer the factor weight approaches 1 , the higher the probability of favoring the contraction. Inversely, the closer the factor weight approaches 0 , the higher the probability of the factor to disfavor the application of the contraction rule.

Several models were fit, with increasing complexity (i.e., increasing number of factors and interactions), including language background (i.e., L1 English, L1 Spanish, Spanish Heritage), L3 Portuguese level (i.e., Level 1, Level 2, Level 2), preposition (i.e., de, em, por, a), article gender (i.e., feminine or masculine), and article number (i.e., singular or plural). The best model was selected based on variance explained (i.e., $\mathrm{R}^{2}$ ) and significance of factor groups (i.e., factor groups that had a $p$ value under our 0.05 alpha).

\section{Results}

\subsection{Overall Distributions}

All three groups presented a high percentage of contraction for preposition + article (i.e., low error rate) across all three L3 Portuguese levels. Table 7 shows the overall distribution of contraction percentage across L1 English, Spanish Heritage, and L3 Portuguese levels. As can be seen, the three groups seemed to behave very similarly, regardless of their linguistic background. In terms of Portuguese levels, one observes a drop in contraction percentage at Level 2, but higher percentages of contraction at Level 3. Based on raw frequencies alone, it is possible to say that Portuguese contractions are mainly acquired in the first semester of instruction and reach near target levels by the third semester.

Table 7. Distribution of percentage of contractions across L1 group and L3 Portuguese level ${ }^{3}$.

\begin{tabular}{lcccc}
\hline & Level 1 (\%) & Level 2 (\%) & Level 3 (\%) & Total Non-Contracted \\
\hline L1 English & 0.97 & 0.96 & 0.99 & $210(2.7 \%)$ \\
Spanish Heritage & 0.96 & 0.95 & 0.99 & $326(3.1 \%)$ \\
L1 Spanish & 0.98 & 0.95 & 0.97 & $107(2.9 \%)$ \\
Total non-contracted & $198(3.4 \%)$ & $303(4.5 \%)$ & $142(1.5 \%)$ & \\
\hline
\end{tabular}


While the raw frequencies in Table 7 demonstrated very similar distributional frequencies across the three language groups, they alone were not able to reveal the impact of linguistic contexts or extra-linguistic factors in the acquisition of contractions by L3 Portuguese learners. Thus, in the next section we submitted our data to logistic regression modeling.

\subsection{Logistic Regression Results}

Logistic regression models were run with participant as a random effect and sum contrasts. This multivariate analysis was able to consider the impact of each independent variable on the realization of contractions in the corpus, thus revealing the trajectory by which they were acquired. The factor groups included in our regression modeling were preposition (i.e., em, de, a, por), definite article number (i.e., singular and plural), definite article gender (i.e., feminine and masculine), L3 Portuguese level (i.e., Level 1, Level 2, and Level 3), and L1 background (i.e., L1 English, L1 Spanish, and Spanish Heritage). The extra-linguistic factor L1 background was not significant, confirming the trend shown in Table 2, i.e., contractions were acquired by L3 learners regardless of their linguistic background. The linguistic factor definite article gender was also not significant, contradicting Brito's (2018) results based on a small sample of spoken data.

Table 8 displays the results of the final logistic regression analysis of the two factors selected as significant to the probability of preposition + article contraction in L3 Portuguese by all three groups of Spanish-English speakers. As shown, the overall probability (i.e., input) of preposition + article contraction was 0.98 , indicating that L3 Portuguese learners had an overall high probability of realizing the obligatory contraction. The highest ranked factor group was preposition, with the preposition $a$ highly favoring contraction with a factor weight of 0.75 , and por favoring non-contraction with a low factor weight of 0.15 . The higher probability that learners will make contractions with a preposition followed by definite articles could signal a possible transfer from Spanish as we hypothesized, since $a$ does contract with $e l$ in this language, a behavior that learners could be generalizing and expanding to all other articles in Portuguese (i.e., $o, o s, a$, and $a s$ ). However, the other preposition that contracts in Spanish is $d e(d e+e l=d e l)$, which showed only a very slight chance of inducing contractions in Portuguese (factor weight 0.56 ), problematizing any conclusions about a facilitatory role of Spanish superficial similarities in learners' production of L3 Portuguese. While contractions with em preposition were also slightly more likely to occur, por strongly favored non-contraction, with an extremely low factor weight of 0.15 . Regarding number, contractions with singular articles were more likely to be realized (factor weight of 0.60) than contractions with plural articles. Transfer from Spanish might explain these results, since only singular articles are contracted with prepositions in Spanish (i.e., de + $e l=d e l$ and $a+\mathrm{e} l=a l)$. Another way that Spanish might be playing a transfer role is in the lack of por + article contractions by L3 Portuguese language, which could stem from the fact that when combined with the singular masculine article $o$, the Portuguese contraction results in pelo, a cognate that in Spanish means "hair." This surface coincidence could be blocking the production of this particular type of contraction (Bybee 2008; Ellis 2006). It is important to note, however, that the direct role of Spanish in the acquisition of these constructions remains conjectural.

3 Note that, due to the large size of our corpus, there were over 100 tokens that were non-contracted for each of the levels for both L3 level and L1 background factor groups. Even with high rates of contraction across L3 levels, all results from the regression models presented in this paper converged, with L3 level being a significant factor in all three models split by L1 background. 
Table 8. Logistic regression of factors conditioning the realization of obligatory preposition + article contraction in L3 Portuguese in a written learners' corpus.

\begin{tabular}{|c|c|c|c|c|c|}
\hline \multicolumn{6}{|c|}{ Input $=0.98$ Total $n=21,879 \mathrm{R}^{2}$ Fixed $=0.12 \mathrm{R}^{2}$ Total $=0.48$} \\
\hline Factor & & $n$ & Proportion & Log Odds & FW \\
\hline \multirow{5}{*}{$\begin{array}{l}\text { Preposition * } \\
\quad p<0.001\end{array}$} & $\mathrm{a}$ & 2300 & 98.74 & 1.07 & 0.75 \\
\hline & em & 8203 & 97.57 & 0.38 & 0.59 \\
\hline & de & 10,394 & 97.17 & 0.26 & 0.56 \\
\hline & por & 982 & 87.68 & -1.71 & 0.15 \\
\hline & & & & RANGE & 60 \\
\hline \multirow{4}{*}{$\begin{array}{l}\text { L3 Portuguese Level * } \\
\qquad p<0.001\end{array}$} & Level 3 & 9398 & 98.49 & 0.81 & 0.70 \\
\hline & Level 1 & 5817 & 96.6 & 0.06 & 0.50 \\
\hline & Level 2 & 6664 & 95.45 & -0.88 & 0.30 \\
\hline & & & & RANGE & 40 \\
\hline \multirow{3}{*}{$\begin{array}{l}\text { Article Number * } \\
\qquad p<0.001\end{array}$} & singular & 17,556 & 97.61 & 0.42 & 0.60 \\
\hline & plural & 4323 & 94.82 & -0.42 & 0.40 \\
\hline & & & & RANGE & 20 \\
\hline \multirow{4}{*}{$\begin{array}{c}\mathrm{L} 1 \\
p>0.05\end{array}$} & L1 English & 7665 & 97.26 & 0.13 & [0.53] \\
\hline & Spanish Heritage & 10,484 & 96.89 & -0.04 & [0.49] \\
\hline & L1 Spanish & 3730 & 97.13 & -0.09 & [0.48] \\
\hline & & & & RANGE & [5] \\
\hline \multirow{3}{*}{$\begin{array}{l}\text { Article Gender } \\
\quad p>0.05\end{array}$} & masculine & 11,975 & 97.30 & 0.08 & [0.52] \\
\hline & feminine & 9904 & 96.77 & -0.08 & {$[0.48]$} \\
\hline & & & & RANGE & [4] \\
\hline
\end{tabular}

${ }^{*}$ significant factor group.

L3 Portuguese level was also significant, but not as strong as preposition. As expected, L3 Portuguese Level 3 (i.e., the highest level) favored contraction with a factor weight of 0.69 . Interestingly, the L3 Portuguese level that least favored contractions (i.e., when L3 Portuguese learners were least likely to realize obligatory contractions) was Level 2 with a factor weight of 0.29 . This indicates that L3 Portuguese Learners realize more contractions in Level 1 than Level 2. This u-shaped pattern is common in L2 acquisition (Eskildsen 2009, 2012), and is clearly shown to be reproduced in L3 acquisition as well.

The remaining factors shown in Table 8 were not significant. The learners' language background did not impact their contraction rates, since not only was this factor group not significant but also all three L1 groups behaved very similarly (range in factor weight of only 5). The lack of importance of language background in the acquisition of this particular construction in Portuguese brought indirect evidence to the claim that heritage speakers do not necessarily present difficulties in controlling morphosyntactic properties in L1 Spanish (Montrul 2010), different from studies that showed that heritage language grammars display simplification of morphosyntactic features (Montrul 2011, p. 158). The current results indicate that for heritage speakers, their knowledge of contractions in Spanish seemed to facilitate the acquisition of Portuguese contractions as much (or as little) as it did for the other language background groups. Finally, and as mentioned, the factor group article gender was also not significant (range in factor weight of only 5), countering Brito's (2018) seminal results about the importance of grammatical gender on the application of contractions in L3 Portuguese.

Once we were able to attest that all language groups and all levels showed similar production of contractions, we then asked if the rate (course levels) and paths of acquisition (preposition type, and article number and gender) were similar across the three language groups. For this purpose, the data were divided by L1 group, and logistic regression with preposition, L3 Portuguese levels, and article gender and number was run for each group, keeping participant as random effect and sum contrasts. Tables 9-11 display these results. The main goal of these separate analyses was to look at the order of factor levels across L1 groups, to investigate the possibility of any differences, and to explore more closely the decrease in contractions from Level 1 to Level 2. 
Table 9. Logistic regression of factors conditioning the realization of obligatory preposition + article contraction in L3 Portuguese for L1 English speakers.

\begin{tabular}{|c|c|c|c|c|c|}
\hline \multicolumn{6}{|c|}{$\begin{array}{c}\text { L1 English } \\
\mathrm{R}^{2} \text { Fixed }=0.15, \mathrm{R}^{2} \text { Total }=0.55\end{array}$} \\
\hline Factor & & $n$ & Proportion & Log Odds & FW \\
\hline \multirow{5}{*}{$\begin{array}{l}\text { Preposition * } \\
\quad p<0.001\end{array}$} & $\mathrm{a}$ & 831 & 98.56 & 0.95 & 0.72 \\
\hline & em & 2924 & 98.08 & 0.68 & 0.66 \\
\hline & de & 3613 & 97.26 & 0.33 & 0.60 \\
\hline & por & 297 & 85.52 & -1.97 & 0.12 \\
\hline & & & & RANGE & 60 \\
\hline \multirow{4}{*}{$\begin{array}{l}\text { L3 Portuguese Level * } \\
\qquad p<0.001\end{array}$} & Level 3 & 2715 & 99.04 & 0.52 & 0.64 \\
\hline & Level 1 & 1844 & 96.85 & 0.4 & 0.59 \\
\hline & Level 2 & 3106 & 95.94 & -0.92 & 0.28 \\
\hline & & & & RANGE & 36 \\
\hline \multirow{3}{*}{$\begin{array}{l}\text { Article Number * } \\
\quad p<0.001\end{array}$} & singular & 6178 & 98.03 & 0.62 & 0.65 \\
\hline & plural & 1487 & 94.08 & -0.62 & 0.35 \\
\hline & & & & RANGE & 30 \\
\hline Article Gender & masculine & 3414 & 97.42 & 0.07 & [0.52] \\
\hline$p>0.05$ & feminine & 4251 & 97.13 & -0.07 & [0.48] \\
\hline
\end{tabular}

Table 10. Logistic regression of factors conditioning the realization of obligatory preposition + article contraction in L3 Portuguese for Spanish Heritage speakers.

\begin{tabular}{|c|c|c|c|c|c|}
\hline \multicolumn{6}{|c|}{$\begin{array}{c}\text { Spanish Heritage } \\
\mathrm{R}^{2} \text { Fixed }=0.14, \mathrm{R}^{2} \text { Total }=0.45\end{array}$} \\
\hline Factor & & $n$ & Proportion & Log Odds & FW \\
\hline \multirow{5}{*}{$\begin{array}{l}\text { Preposition * } \\
\quad p<0.001\end{array}$} & $a$ & 1061 & 98.96 & 1.29 & 0.78 \\
\hline & de & 5018 & 97.05 & 0.17 & 0.55 \\
\hline & em & 3881 & 97.09 & 0.09 & 0.52 \\
\hline & por & 524 & 89.69 & -1.56 & 0.18 \\
\hline & & & & RANGE & 60 \\
\hline \multirow{4}{*}{$\begin{array}{l}\text { L3 Portuguese Level * } \\
\qquad p<0.001\end{array}$} & Level 3 & 4549 & 98.66 & 0.91 & 0.71 \\
\hline & Level 1 & 3109 & 96.11 & -0.10 & 0.47 \\
\hline & Level 2 & 2826 & 94.90 & -0.81 & 0.31 \\
\hline & & & & RANGE & 40 \\
\hline \multirow{3}{*}{$\begin{array}{l}\text { Article Number * } \\
\quad p<0.001\end{array}$} & singular & 8467 & 97.40 & 0.36 & 0.59 \\
\hline & plural & 2017 & 94.74 & -0.36 & 0.41 \\
\hline & & & & RANGE & 18 \\
\hline \multirow{3}{*}{$\begin{array}{l}\text { Article Gender * } \\
\quad p<0.05\end{array}$} & masculine & 5680 & 97.25 & 0.14 & 0.54 \\
\hline & feminine & 4804 & 96.46 & -0.14 & 0.46 \\
\hline & & & & RANGE & 7 \\
\hline
\end{tabular}

\footnotetext{
${ }^{*}$ significant factor group.
}

Data derived from Tables 9 and 10 are summarized in Table 12, which displays the prepositions that most favored target-like contractions, the pace of acquisition in each language group, and the impact of article number on favoring target-like Portuguese contractions. 
Table 11. Logistic regression of factors conditioning the realization of obligatory preposition + article contraction in L3 Portuguese for L1 Spanish speakers.

\begin{tabular}{|c|c|c|c|c|c|}
\hline \multicolumn{6}{|c|}{$\begin{array}{c}\text { L1 Spanish } \\
R^{2} \text { Fixed }=0.11, R^{2} \text { Total }=0.56\end{array}$} \\
\hline \multicolumn{2}{|l|}{ Factor } & $n$ & Proportion & Log Odds & FW \\
\hline \multirow{5}{*}{$\begin{array}{l}\text { Preposition * } \\
\quad p<0.001\end{array}$} & $\mathrm{a}$ & 408 & 98.53 & 0.78 & 0.69 \\
\hline & em & 1398 & 97.85 & 0.65 & 0.66 \\
\hline & de & 1763 & 97.33 & 0.34 & 0.58 \\
\hline & por & 161 & 85.09 & -1.77 & 0.15 \\
\hline & & & & RANGE & 54 \\
\hline \multirow{4}{*}{$\begin{array}{l}\text { L3 Portuguese Level * } \\
\qquad p<0.001\end{array}$} & Level 3 & 2134 & 97.42 & 0.87 & 0.70 \\
\hline & Level 1 & 864 & 97.80 & 0.11 & 0.52 \\
\hline & Level 2 & 732 & 95.49 & -0.98 & 0.28 \\
\hline & & & & RANGE & 42 \\
\hline \multirow{3}{*}{$\begin{array}{l}\text { Article Number } \\
\qquad p>0.05\end{array}$} & singular & 2911 & 97.35 & 0.20 & [0.55] \\
\hline & plural & 819 & 96.34 & -0.20 & [0.45] \\
\hline & & & & RANGE & [10] \\
\hline \multirow{3}{*}{$\begin{array}{l}\text { Article Gender } \\
\quad p>0.05\end{array}$} & masculine & 2044 & 97.80 & 0.13 & [0.53] \\
\hline & feminine & 1686 & 96.32 & -0.13 & [0.47] \\
\hline & & & & RANGE & {$[6]$} \\
\hline
\end{tabular}

* significant factor group.

Table 12. The impact of preposition type and course level on the production of contractions among L3 Portuguese learners in order of probability factor weights (non-significant results are indicated with N.S.).

\begin{tabular}{ccccc}
\hline Factors & Factor Weight & L1 English & Spanish Heritage & L1 Spanish \\
\hline \multirow{3}{*}{ Preposition } & & a & a & a \\
& $>0.5$ & $\begin{array}{c}\text { em } \\
\text { de }\end{array}$ & em & $\begin{array}{c}\text { em } \\
\text { de }\end{array}$ \\
\cline { 2 - 5 } & $<0.5$ & por & por & por \\
\hline \multirow{2}{*}{ Course Level } & $>0.5$ & Level 3 & Level 3 & Level 3 \\
& & Level 1 & Level 1 & Level 1 \\
\hline \multirow{2}{*}{ Article Number } & $>0.5$ & Level 2 & Level 2 & Level 2 \\
& $>0.5$ & Singular & Singular & N.S. \\
\hline \multirow{2}{*}{ Article Gender } & $<0.5$ & Plural & Plural & N.S. \\
& $>0.5$ & N.S. & Masculine & N.S. \\
& $<0.5$ & N.S. & Feminine & N.S. \\
\hline
\end{tabular}

A first glance at the results organized on Table 12 shows a strikingly uniform pattern across the three language groups, with each factor group showing similar factor group rankings (which factors were shown to be significant, and in what order), and constraint rankings (or how factors were ordered within selected factor groups). The most impactful factor group in the realization of contractions, preposition type, showed strong similarities across the three language groups, while $a$ was the strongest factor to favor contraction, the preposition por remained the least favored for contraction across all three groups. While the positive impact of $a$ in favoring target-like contractions can be due to transfer from Spanish $(a+e l=a l)$, it is possible that the lack of contraction with por might be explained by blocking (Ellis 2006), due to its similarity in the form of the pelo contraction in Portuguese $(p o r+o)$ to the cognate in Spanish ("hair"). The L1 English and L1 Spanish groups displayed the exact same order of factors for preposition, with em favoring contraction more strongly than $d e$. The Spanish Heritage group, however, inverted that order slightly, with de favoring contraction slightly more strongly than 
$e m$. It is important to note that the difference between these two prepositions was very small for heritage speakers of Spanish, indicating that they realized contractions at the same rate for both $d e$ and $\mathrm{em}$. While $\mathrm{em}$ consistently presented probability rates slightly above 0.5 , which indicated near neutrality for contraction realization, the role of por preposition may be explained by a conflict in form mapping (Ellis 2006), with the pelo form mapping to the lexical item that means "hair" in Spanish and to the preposition + article contraction in Portuguese.

In addition, all three groups displayed the same order of factors for L3 Portuguese level, with Level 3 favoring contraction more strongly and Level 2 favoring non-contraction, revealing that acquisition of obligatory preposition + article contractions in Portuguese took place for all groups. As such, our results provide evidence that acquisition takes place, no matter how difficult the morphosyntactic pattern (Bybee 2008). Acquisition of the categorical rule of contraction in L3 Portuguese was u-shaped for language groups, i.e., Level 2 was the level where learners least favored the realization of obligatory contractions in Portuguese. This again was expected, since nonlinear acquisition patterns have been attested in second language acquisition research (Eskildsen 2009, 2012). It is important to keep in mind that language levels were based on the participants' enrollment in the first, second, and third semesters, although it is well known that learners' proficiency does not necessarily correlate to course level. However, given that L3 Portuguese level was a significant factor group in all regression runs and individuals were included as a random factor, it is possible to claim that the oscillation of factor weights across L1 groups and L3 levels indeed presented another case of $\mathrm{u}$-shaped acquisition, as illustrated in Figure 2.

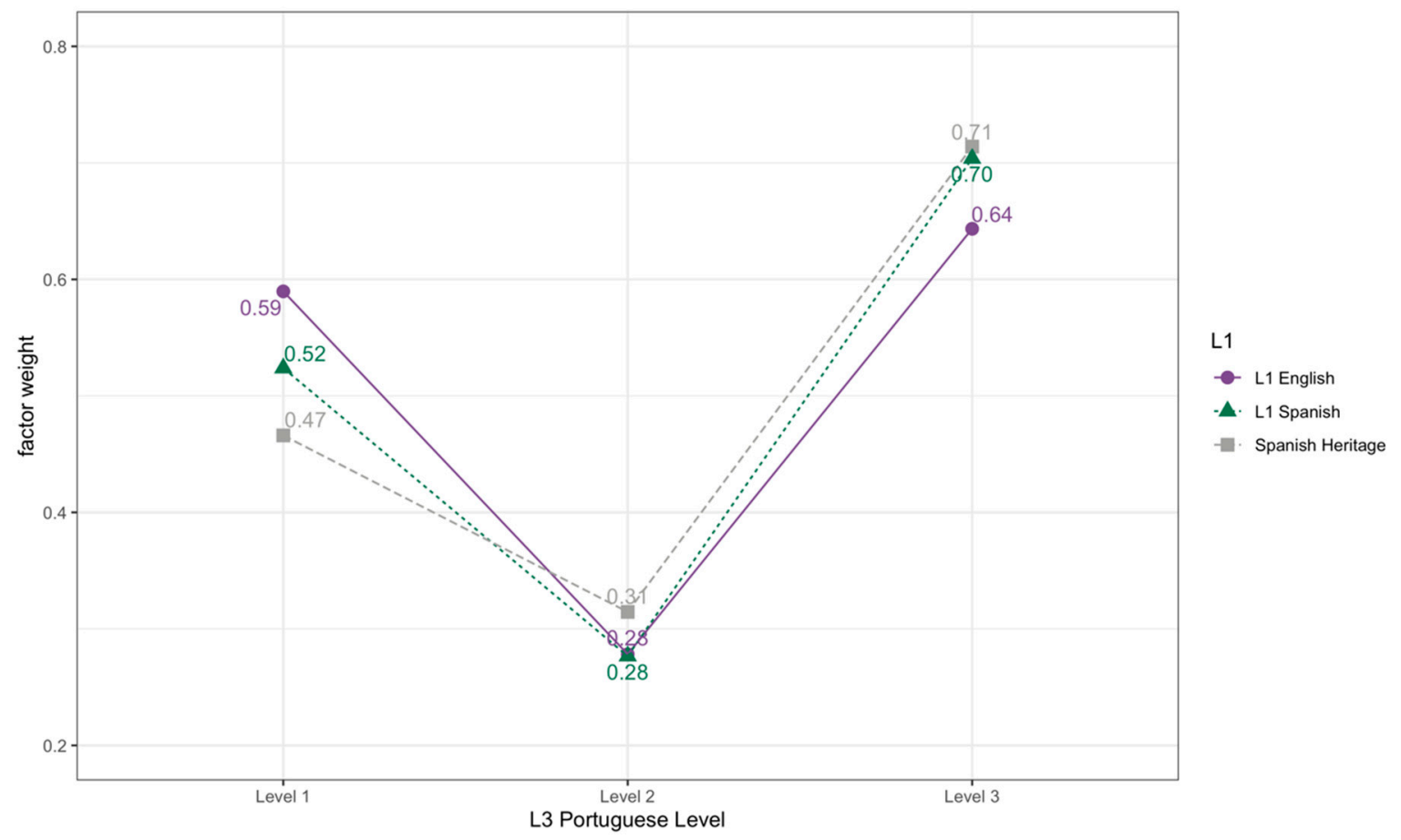

Figure 2. Factor weight (FW) across L3 Portuguese levels according to language background.

Finally, both L1 English and Heritage speakers displayed article number as a significant factor group, with singular favoring contraction (FW $=0.65$ for L1 English, and FW $=0.59$ for Spanish Heritage). Article number and gender were not significant factors for the L1 Spanish group. This surprising result points to the possibility that linguistic congruence across Spanish and Portuguese in regard to the roles of article number and gender in generating contractions does not translate in transfer patterns to all language groups equally. In fact, L1 Spanish speakers seemed to be the least likely to associate the role of the singular masculine article $e l$ behind contractions with prepositions $a$ and $d e$ in Spanish, 
a behavior that favored the higher probability that contractions are formed with singular articles by L1 English and singular masculine articles by Spanish Heritage speakers.

\section{Conclusions}

This variationist analysis of preposition + article contractions enabled us to revisit the role of Spanish in the acquisition of L3 Portuguese by English-Spanish bilinguals from the usage-based approach to language acquisition. We found that, crucially, all language groups (i.e., L1 English, Spanish Heritage, and L1 Spanish speakers) acquired contractions at the same rate (Table 6). If learners were indeed borrowing from the $a+e l$ and $d e+e l$ contractions in Spanish in their performance in Portuguese, one may conclude that the facilitatory role of a cognate L1 in transfer patterns during L3 acquisition is available for all Spanish speakers, regardless of the context of acquisition of Spanish, as claimed by Alonso and Rothman (2016) and Montrul, and Dias and Santos (Montrul et al. 2010).

In addition, the logistic regression analysis that allowed for a comparison of the pace and path of acquisition for the three language groups showed that, first, apparent time data demonstrate that as expected, most learners acquired Portuguese contractions during instruction, since third-semester students showed a significant positive probability of using them when compared to first and second semesters. The pace of acquisition was the same for all three language groups; regardless of the way Spanish was acquired, all learners showed a great deal of acquisition in the first semester, a decline in the second, and progress in the third semester, where contractions were realized almost categorically, resembling target-like behavior. This result answers our first research question by showing that all three groups showed the same developmental pattern, since contractions were acquired at a similar pace. We then conclude that obligatory contractions are acquired at the same pace, regardless of L3 learner's L1 background.

In addition, in answering our second question, this analysis revealed some of the acquisitional paths that learners take during acquisition of Portuguese contractions. First, it is clear that the type of preposition impacts the realization of contractions. All language background groups showed higher probabilities that contractions are likely to be realized in constructions involving the $a$ preposition and very unlikely to be realized when the construction involves the por preposition. Em and de prepositions occupy the middle of the probability scale, with $\mathrm{em}$ being favored slightly more by heritage speakers of Spanish than $d e$, a pattern that was reversed in the other two language groups. It is important to note here that contractions with $\mathrm{de}$ and $\mathrm{em}$ for heritage speakers of Spanish showed no significant difference. In other words, while L1 English and L1 Spanish showed a tendency toward contracting de more often than $\mathrm{em}$, heritage speakers of Spanish did not show that tendency. Also important was article number (i.e., plural vs. singular), since it was a significant factor for the L1 English and Spanish Heritage groups, but not for L1 Spanish speakers. In addition, article gender was significant among heritage Spanish-speaking learners, who, as expected, showed higher probabilities of replicating target-like contractions when the article was masculine as opposed to feminine, modeling the Spanish rule of contractions with masculine articles only. While this tendency was also seen in the other two language groups, it failed to reach significance. We thus conclude that linguistic contexts across different L1 groups affect how prepositions are acquired gradually according to the preposition type, in all groups, but we detected small differences in terms of the magnitude of the impact of the factors on the realization of the contraction rule according to language group, albeit very similar tendencies (as shown on Table 11).

Finally, our third question is only partially answered. On one hand, it seems that our results support the Typological Primacy Model (Rothman 2010a), which predicts transfer from Spanish for all groups, as evidenced by the acquisition of the $a$ preposition contraction (also productive in Spanish). In addition, the strong negative impact of the por preposition, one that, when contracted, results in pelo, a word with a different meaning in Spanish, could signal blocking due to the role of Spanish as well. The difficulty presented by all three L1 groups in acquiring pelo might also be explained by language internal factors, which are determined by the construction itself rather than by transfer from 
Spanish. Finally, the fact that singular articles favor contractions more than plural, at least among L2 and heritage Spanish-speaking learners, and masculine gender favors contractions more than feminine among heritage Spanish-speaking learners added to the hypothesis that learners do capitalize on similarities found in their linguistic repertoire in L3 production. However, the role of Spanish is only partially confirmed, since the lack of a faciliatory impact of constructions with de preposition (also productive in Spanish) was also attested by all three language groups. It would also be interesting to verify whether L2 learners (for both Spanish and English speakers) present similar trajectories in their acquisition of Portuguese contractions, or if $\mathrm{L} 3$ learners indeed experience a faster acquisition process as predicted (Cenoz 2013). Further research could also include experimental tasks, which are more controlled than the corpus data we made use of in this study, to investigate further the acquisition of preposition + article contractions in Portuguese.

In conclusion, this study highlights the importance of taking a usage-based approach to L3 language development by making use of corpus data to shed light on the cognitive representation of L3 Portuguese being perpetually modified by use (Geeslin and Long 2014). The constant building and rebuilding of cognitive representations of language constructions also explain the nonlinearity of language development (i.e., u-shaped learning) evidenced in this study.

Author Contributions: Conceptualization, A.M.C.; Data curation, A.P.; Formal analysis, A.P.; Investigation, A.P.; Methodology, A.P. and A.M.C.; Project administration, A.P.; Resources, A.P.; Software, A.P.; Validation, A.P.; Visualization, A.P.; Writing_original draft, A.P.; Writing—review \& editing, A.P. and A.M.C. All authors have read and agreed to the published version of the manuscript.

Funding: This research was funded in part by CERCLL Title VI grant from the U.S. Department of Education.

Conflicts of Interest: The authors declare no conflict of interest.

\section{References}

Alonso, Jorge González, and Jason Rothman. 2016. Coming of age in 13 initial stages transfer models: Deriving developmental predictions and looking towards the future. International Journal of Bilingualism 21: 683-97. [CrossRef]

Amaral, Luiz, and Detmar W. Meurers. 2009. Little things with big effects: On the identification and interpretation of tokens for error diagnosis in ICALL. CALICO Journal 26: 580-91. [CrossRef]

Amaro, Jennifer Cabrelli. 2017. Testing the phonological permeability hypothesis: L3 phonological effects on L1 versus L2 systems. International Journal of Bilingualism 21: 698-717. [CrossRef]

Amaro, Jennifer Cabrelli, João Felipe Amaro, and Jason Rothman. 2015. The relationship between L3 transfer and structural similarity across development: Raising across an experiencer in brazilian portuguese. In Transfer Effects in Multilingual Language Development. Edited by Hagen Peukert. Amsterdam: John Benjamins Publishing Company, vol. 4, pp. 21-52.

Bates, Douglas, Martin Mächler, Benjamin Bolker, and Steven Walker. 2015. Fitting Linear Mixed-Effects Models Using lme4. Journal of Statistical Software 67: 1-48. [CrossRef]

Brito, Edvan P. 2018. The variation of obligatory preposition-article contractions in the interlanguage of adult learners of Portuguese. Revista do GEL 15: 241-56. [CrossRef]

Bybee, Joan. 2008. Usage-based grammar and second language acquisition. In Handbook of Cognitive Linguistics and Second Language Acquisition. Edited by Peter Robinson and Nick C. Ellis. London: Routledge, pp. 226-46.

Carvalho, Ana Maria, and Antônio José Bacelar Da Silva. 2006. Cross-linguistic influence in third language acquisition: The case of spanish-english bilinguals' acquisition of portuguese. Foreign Language Annals 39: 185-202.

Cenoz, Jasone. 2013. The influence of bilingualism on third language acquisition: Focus on multilingualism. Language Teaching 46: 71-86. [CrossRef]

Child, Michael W. 2014. Cross-Linguistic Influence in 13 Portuguese Acquisition: Language Learning Perceptions and the Knowledge and Transfer of Mood Distinctions by Three Groups of English-Spanish Bilinguals. Ph.D. thesis, University of Arizona, Tucson, Arizona.

De Angelis, Gessica. 2007. Third or Additional Language Acquisition. Multilingual Matters. Clevendon: Multilingual Matters LTD. 
Dickerson, Lonna J. 1975. Internal and external patterning of phonological variability in the speech of Japanese learners of English: Toward a theory of second-language acquisition. Dissertation abstracts international. The Humanities and Social Sciences 35: 7285-86.

Ellis, Nick C. 2006. Selective attention and transfer phenomena in L2 acquisition: Contingency, cue competition, salience, interference, overshadowing, blocking, and perceptual learning. Applied Linguistics 27: 164-94. [CrossRef]

Ellis, Nick. 2015. Cognitive and Social Aspects of Learning from Usage. In Usage-Based Perspectives on Second Language Learning. Edited by Teresa Cadierno and Søren Wind Eskildsen. Berlin: De Gruyter.

Eskildsen, Søren Wind. 2009. Constructing another language-Usage-based linguistics in second language acquisition. Applied linguistics 30: 335-57. [CrossRef]

Eskildsen, Søren Wind. 2012. L2 negation constructions at work. Language Learning 62: 335-72. [CrossRef]

Eskildsen, Søren, and Teresa Cadierno. 2015. Advancing usage-based approaches to L2 studies. In Usage-Based Perspectives on Second Language Learning. Edited by Teresa Cadierno and Søren Wind Eskildsen. Berlin: De Gruyter.

Forsyth, Helen. 2014. The influence of 12 transfer on 13 english written production in a bilingual german/italian population: A study of syntactic errors. Open Journal of Modern Linguistics 4: 429-56. [CrossRef]

Geeslin, Kimberly L., and Avizia Yim Long. 2014. Sociolinguistics and Second Language Acquisition: Learning to Use Language in Context. London: Routledge.

Giancaspro, David, Becky Halloran, and Michael Iverson. 2015. Transfer at the initial stages of L3 Brazilian Portuguese: A look at three groups of english/spanish bilinguals. Bilingualism: Language and Cognition 18: 191-207. [CrossRef]

Goldberg, Adele E. 2006. Constructions at Work: The Nature of Generalization in Language. Oxford: Oxford University Press.

Johnson, Daniel Ezra. 2009. Getting off the GoldVarb standard: Introducing Rbrul for mixed-effects variable rule analysis. Language and Linguistics Compass 3: 359-83. [CrossRef]

Kemmer, Suzanne, and Michael Barlow. 2000. Introduction: A usage-based conception of language. In Usage-Based Models of Language. Edited by Michael Barlow and Suzanne Kemmer. Stanford: CSLI Publications.

Montrul, Silvina. 2010. How similar are adult second language learners and Spanish heritage speakers? Spanish clitics and word order. Applied Psycholinguistics 31: 167-207. [CrossRef]

Montrul, Silvina. 2011. The linguistic competence of heritage speakers. Studies in Second Language Acquisition 33: 155-61. [CrossRef]

Montrul, Silvina, Rejanes Dias, and Hélade Santos. 2010. Clitics and object expression in the L3 acquisition of Brazilian Portuguese: Structural similarity matters for transfer. Second Language Research 27: 21-58. [CrossRef]

Nunes, Jairo, and Cristina Ximenes. 2008. Preposition contraction and morphological sideward movement in Brazilian Portuguese. In Minimalist Essays on Brazilian Portuguese Syntax. Edited by Jairo Nunes. Amsterdam: John Benjamins, pp. 156-77.

Preston, Dennis R. 1996. Variationist perspectives on second language acquisition. In Second Language Acquisition and Linguistic Variation. Edited by Robert Bayley and Dennis R. Preston. Amsterdam: John Benjamins, pp. 1-45. [CrossRef]

R Core Team. 2020. R: A Language and Environment for Statistical Computing. Vienna: R Foundation for Statistical Computing, Available online: https://www.R-project.org/ (accessed on 31 August 2020).

Rothman, Jason. 2010a. L3 syntactic transfer selectivity and typological determinacy: The typological primacy model. Second Language Research 27: 107-27. [CrossRef]

Rothman, Jason. 2010b. On the typological economy of syntactic transfer: Word order and relative clause high/low attachment preference in L3 Brazilian Portuguese. International Review of Applied Linguistics in Language Teaching 48: 245-73. [CrossRef]

Tagliamonte, Sali A. 2006. Analysing Sociolinguistic Variation. Cambridge: Cambridge University Press.

Tagliamonte, Sali A. 2012. Variationist Sociolinguistics: Change, Observation, Interpretation. 39 vols. Hoboken: John Wiley and Sons.

Tarone, Elaine. 2007. Sociolinguistic approaches to second language acquisition research-1997-2007. The Modern Language Journal 91: 837-48. [CrossRef]

Tomasello, Michael. 2009. Constructing a language. In A Usage-Based Theory of Language Acquisition. Cambridge: Harvard University Press. 
Wulff, Stefanie, and Nick C. Ellis. 2018. Usage-Based Approaches to Second Language Acquisition. Amsterdam: John Benjamins, vol. 54, pp. 37-56.

Ximenes, Cristina. 2004. Preposition contraction in coordinated structures in Brazilian Portuguese. MIT Working Papers in Linguistics 47: 179-94.

Publisher's Note: MDPI stays neutral with regard to jurisdictional claims in published maps and institutional affiliations.

(C) 2020 by the authors. Licensee MDPI, Basel, Switzerland. This article is an open access article distributed under the terms and conditions of the Creative Commons Attribution (CC BY) license (http://creativecommons.org/licenses/by/4.0/). 